\title{
Growing dairy heifers prefer supplementary long straw when fed a nutrient-dense ration in a limited amount
}

\author{
A. M. Greter, ${ }^{*}$ M. Prinsen, ${ }^{*}$ T. F. Duffield, $†$ B. W. McBride, $\ddagger$ T. M. Widowski, $\ddagger$ and T. J. DeVries ${ }^{* 1}$ \\ *Department of Animal and Poultry Science, University of Guelph, Kemptville Campus, 830 Prescott Street, Kemptville, ON, K0G 1J0, Canada \\ †Department of Population Medicine, Ontario Veterinary College, University of Guelph, 50 Stone Road E, Guelph, ON, N1G 2W1, Canada \\ ‡Department of Animal and Poultry Science, University of Guelph, 50 Stone Road E, Guelph, ON, N1G 2W1, Canada
}

\begin{abstract}
The objective of this study was to determine whether limit-fed heifers will choose to consume long particles, rather than short, of a low-nutritive feedstuff to ameliorate rumen function and meet foraging needs. Ten Holstein heifers $261.6 \pm 39.2($ mean $\pm \mathrm{SD}) \mathrm{d}$ of age were exposed to each of 2 dietary treatments, in a random order, over 2 successive 7 -d treatment periods (4-d adaptation period and a 3 -d data collection period) using a crossover design. The treatments were (1) a provision of long particle oat straw ( $85 \%$ of particles $>8 \mathrm{~mm}$; LS) and (2) provision of short particle oat straw (45\% of particles $>8 \mathrm{~mm}$; SS). Both treatments were offered following consumption of a limit-fed, nutrient-dense total mixed ration fed at $2.05 \%$ of body weight. Following each 7-d period, heifers were given access to both types of straw during an additional 2-d preference period; individual intakes were recorded daily. Feeding and lying behavior were recorded during the last $3 \mathrm{~d}$ of each treatment period. Ruminal temperature was recorded during the last $3 \mathrm{~d}$ of each treatment period using a telemetric acquisition system and rumen boluses. Dry matter intake of both the total mixed ration $(6.3 \mathrm{~kg} / \mathrm{d})$ and straw $(0.36 \mathrm{~kg} / \mathrm{d})$ was similar between treatments. Heifers fed LS spent more time feeding (197.7 vs. 175.2 $\mathrm{min} / \mathrm{d}$ ) throughout the day than heifers fed SS due to the increase in time required to consume long particles in the LS (59.8 vs. $34.2 \mathrm{~min} / \mathrm{d}$ ). Daily lying time (974.7 $\mathrm{min} / \mathrm{d}$ ) and time spent standing without eating (278.9 min/d) was similar between treatments. The preference period showed a strong preference ratio for LS rather than SS (preference ratio $=0.83$ ), with heifers consuming $0.43 \pm 0.2 \mathrm{~kg} / \mathrm{d}$ of LS and $0.07 \pm 0.1 \mathrm{~kg} / \mathrm{d}$ of SS (mean $\pm \mathrm{SD}$ ). Heifers maintained similar mean $\left(38.3^{\circ} \mathrm{C}\right)$, minimum $\left(35.1^{\circ} \mathrm{C}\right)$, and maximum $\left(38.9^{\circ} \mathrm{C}\right)$ rumen temperature across treatments. The amount of time that rumen temperature was elevated over $38.6^{\circ} \mathrm{C}$,
\end{abstract}

Received January 26, 2013.

Accepted February 24, 2013.

${ }^{1}$ Corresponding author: tdevries@uoguelph.ca $39.0^{\circ} \mathrm{C}$, and $39.4^{\circ} \mathrm{C}$ was similar between treatments. In conclusion, heifers will consume similar amounts of supplementary long or short straw if provided to them alongside of a limit-fed TMR. Limit-fed heifers do, however, show a clear preference for LS when offered the choice, suggesting that they find LS to be more satisfactory for achieving rumen fill or meeting their behavioral foraging needs.

Key words: dairy heifer, feeding behavior, limit feeding, preference

\section{INTRODUCTION}

Limit feeding has drawn attention in recent years because it offers great potential to reduce the costs associated with raising replacement dairy heifers. Feeding a nutrient-dense ration in a limited amount (restricted to $80-90 \%$ of ad libitum intake) has the potential to reduce feed costs and nutrient or fecal excretion, as well as improve feed efficiency (Hoffman et al., 2007; Lascano et al., 2009). Despite these benefits, limit feeding also poses several concerns. For instance, limit-fed heifers spend much less time feeding $(\sim 1-2 \mathrm{~h}$; restricted to $70-80 \%$ of ad libitum intake; Greter et al., 2011; Kitts et al., 2011) daily than ad libitum-fed heifers raised under intensive $(3-5 \mathrm{~h}$; Greter et al., 2008; DeVries and von Keyserlingk, 2009) or extensive (4-9 h; Kilgour, 2012) environments. Additionally, Hoffman et al. (2007) found an increase in vocalizations, standing without eating, and aggressive reaching for feed in limit-fed heifers. Limit feeding cattle has also been associated with an increase in oral stereotypies, such as bar biting, head nodding, and tongue rolling or playing (restricted to $80-85 \%$ of ad libitum intake; Redbo et al., 1996; Lindström and Redbo, 2000). These behavioral changes may be associated with hunger and frustration due to lack of satiety (restricted to 25-50\% of ad libitum intake; Savory et al., 1993), or frustration due to lack of foraging substrate (Lindström and Redbo, 2000). Finally, limit-fed heifers may experience more severe depressions in rumen $\mathrm{pH}$ as a result of rapidly consuming a diet composed mainly of highly 
fermentable carbohydrates, thereby increasing the risk for development of subacute ruminal acidosis or other problems with rumen fermentation (Stone, 2004; Moody et al., 2007).

Providing supplementary straw alongside a limit-fed TMR has recently been found to help alleviate some of these behavioral concerns. Heifers offered straw in addition to their TMR spent more time feeding and had higher DMI, while still gaining benefit from feed efficiency, when compared with animals that are fed ad libitum a high-forage diet (Greter et al., 2011; Kitts et al., 2011). However, it is not clear whether animals were consuming straw due to hunger, a behavioral foraging need, or in an effort to ameliorate depressed rumen pH. Lindström and Redbo (2000) demonstrated that lactating dairy cows were motivated to spend time manipulating their feed, whether the rumen was full or not. These findings suggest that, even though the cattle may be physiologically full, they may have a behavioral need to perform feeding behaviors. Furthermore, Keunen et al. (2002) found that following induction of subacute ruminal acidosis, dairy cattle offered alfalfa pellets and long alfalfa hay altered their feeding in preference of the long hay. Those researchers speculated that this was likely due to the increased buffering capacity of long hay due to increased chewing resulting in increased salivary secretion. Thus, the cows were selecting the alternative that would best attenuate the depressed rumen $\mathrm{pH}$ (Keunen et al., 2002). The objective of the experiment reported in this paper was to determine whether limit-fed heifers will choose to consume long particles, rather than short, of a lownutritive feedstuff (i.e., straw) to ameliorate rumen health and meet foraging needs. We hypothesized that heifers will consume larger amounts of long straw in comparison to short straw.

\section{MATERIALS AND METHODS}

\section{Animals and Housing}

Ten Holstein dairy heifers were used in this study. Heifers were $261.6 \pm 39.2$ (mean $\pm \mathrm{SD}$ ) d of age and weighed $303.3 \pm 56.2 \mathrm{~kg}$ at the beginning of the study and weighed $316.2 \pm 59.8 \mathrm{~kg}$ at the end of the study. Heifers were housed in a tiestall barn at the University of Guelph, Kemptville Campus, and were managed according to the guidelines set by the Canadian Council on Animal Care (2009). Use of heifers was approved by the University of Guelph's Animal Care Committee (AUP\#09R022). The study was conducted between April and May 2012. Each heifer was individually housed in a tiestall $(203 \times 124.5 \times 91 \mathrm{~cm} ; \mathrm{L} \times \mathrm{W} \times$ $\mathrm{H})$, bedded with wood shavings, where each individual had ad libitum access to water (via its own water bowl) and access to a limit-fed ration via their own feed bunk (individual feed bunks were separated with dividers). Orts (if any) were cleaned out of feed bunks at $0900 \mathrm{~h}$ each day. Heifers were given a 2 -h exercise period (0900 to $1100 \mathrm{~h}$ ) each day in an outdoor dry lot pen. Heifers were given ad libitum access to trace mineral salt blocks while in the exercise yard (Windsor TM Stock Salt, The Canadian Salt Company Ltd., Pointe-Claire, Canada).

\section{Experimental Design and Rations}

The number of animals required per treatment was determined through power analysis (Morris, 1999) for primary response variables, including DMI and feeding behavior. Estimates of variation for these variables were based on previously reported values (Kertz and Chester-Jones, 2004; Greter et al., 2008; Kitts et al., 2011). Heifers were fed a nutrient-dense TMR (Table 1) that was formulated to meet the nutrient requirements for a nonbred Holstein heifer growing at $0.9 \mathrm{~kg} / \mathrm{d}$ (NRC, 2001) and fed at a restricted level $(2.05 \%$ of BW). During the first $7 \mathrm{~d}$ of a 14-d adaptation period, heifers were given extra haylage to facilitate gradual adaptation of rumen microbes to the nutrient-dense ration. The amount of extra haylage was decreased by $5 \%$ each day over the 7 -d period. Heifers then spent the additional $7 \mathrm{~d}$ of the 14-d adaptation period consuming solely the formulated nutrient-dense ration.

Following the adaptation period, heifers were exposed to each of 2 dietary treatments, in a random order, over 2 successive 7 -d treatment periods using a crossover design. These treatment periods included a 4-d adaptation period and a 3 -d data collection period. The treatments were (1) a provision of long-particle oat straw $(85 \%$ of particles $>8 \mathrm{~mm}$; LS) or (2) a provision of short-particle oat straw ( $45 \%$ of particles $>8$ $\mathrm{mm} ; \mathbf{S S}$ ). Both treatments were offered following consumption of a limit-fed, nutrient-dense TMR. Heifers in adjacent stalls were on different treatments. Short straw was chopped using a straw chopper with a 2.54cm screen (355 Grinder-Mixer, New Holland Inc., New Holland, PA). Straw was offered in 2 different bins with long straw available in a larger bin $(64.1 \times 41.9 \times$ $38.7 \mathrm{~cm} ; \mathrm{L} \times \mathrm{W} \times \mathrm{H})$ than short straw $(76.8 \times 52.1$ $\times 41.9 \mathrm{~cm})$. The location of each bin within the feed bunk was kept constant within heifers but alternated between heifers (e.g., heifer 1 had long straw on right side, short straw on left side, whereas heifer 2 had long straw on left side, short straw on right side). The different sizes of the straw bins and the constant location were used to facilitate association of the straw length with its postingestive feedback and to avoid confusion 
Table 1. Ingredient, chemical composition, calculated nutrients, and particle size (mean $\pm \mathrm{SD})$ of the TMR

\begin{tabular}{lc}
\hline Composition & Measurement \\
\hline Ingredient (\% of DM) & \\
Corn silage & 31 \\
Grass/alfalfa haylage & 32 \\
High-moisture corn & 26 \\
Protein supplement $^{1}$ & 11 \\
Chemical composition & \\
DM (\%) & \\
OM (\% of DM) & $49.1 \pm 2.5$ \\
CP (\% of DM) & $92.3 \pm 0.3$ \\
ADF (\% of DM) & $14.7 \pm 1.1$ \\
NDF (\% of DM) & $20.3 \pm 0.6$ \\
NFC (\% of DM) & $34.2 \pm 1.3$ \\
Calculated nutrients ${ }^{3}$ & $39.9 \pm 2.8$ \\
TDN $(\%$ of DM) & $73.1 \pm 0.7$ \\
ME (Mcal/kg) & $2.64 \pm 0.03$ \\
NE $(\mathrm{Mcal} / \mathrm{kg})$ & $1.11 \pm 0.02$ \\
NE $(\mathrm{Mcal} / \mathrm{kg})$ & $1.73 \pm 0.02$ \\
Particle size $(\%)$ & \\
Long $^{5}$ Medium & $7.4 \pm 3.3$ \\
Short & $46.2 \pm 0.7$ \\
Fine & $39.1 \pm 2.0$ \\
\hline
\end{tabular}

${ }^{1}$ Supplied by Dundas Feed and Seed (Winchester, Canada), containing (on as-is basis) $25.6 \%$ corn gluten meal, 24.4\% Tri-Pro Gold (TriCounty Protein Corp., Winchester, Canada), 24.4\% soybean meal, $10.0 \%$ canola meal, $4.8 \%$ ground limestone, $4.5 \%$ trace mineral/vitamin premix, $4.4 \%$ sodium bicarbonate, $1.9 \%$ cobaltized-iodized salt.

${ }^{2}$ Values were obtained from chemical analysis of TMR samples. NFC $=100-(\% \mathrm{CP}+\% \mathrm{NDF}+\%$ fat $+\%$ ash $)$.

${ }^{3}$ Calculated according to NRC (2001) equations.

${ }^{4}$ Total digestible nutrients (calculated from ingredients).

${ }^{5}$ Particle size determined by Penn State Particle Separator, which has a 19-mm screen (long), 8-mm screen (medium), 1.18-mm screen (short), and a pan (fine).

(Forbes, 2007). Once daily, dietary components were mixed in a TMR mixer wagon (Jaylor 4425, Jaylor Fabricating, Orton, Canada). The appropriate amount of TMR was manually weighed out for each heifer. The total amount of feed offered to each heifer was adjusted weekly, according to total heifer BW. The ration DM used to calculate the feed amount was adjusted every 2 wk. Heifers were fed their TMR at $1100 \mathrm{~h}$ and offered straw at $1600 \mathrm{~h}$ daily.

Following these 7 -d periods of exposure to each type of straw (long and short), heifers were given access to both types of straw during an additional 2-d period to determine preference. The feeding management of heifers during this time period was similar to the exposure weeks with the exception of having access to both straw lengths.

\section{Experimental Measurements}

Individual intakes were recorded daily throughout the study by weighing the amount of feed offered and amount of feed refused (if any) using a calibrated floor scale precise to the nearest $0.1 \mathrm{~kg}$ (Model 31-0851T17430, Toledo Scale Company of Canada Ltd., Windsor, Canada). This data was used to calculate daily DMI $(\mathrm{kg} / \mathrm{d})$. Heifers were weighed on the same 2 consecutive days each week and these weekly weights were averaged for each heifer and used to calculate BW to determine feed amounts.

Feeding behavior was monitored continuously, using time-lapse video, for the $7 \mathrm{~d}$ of each treatment period and the $2 \mathrm{~d}$ of the preference test. Heifers were recorded using 4 video cameras (Panasonic WV-BP330; Osaka, Japan), a time-lapse video cassette recorder (Panasonic AG-6740), and a video multiplexer (Panasonic WJ-FS 616). Each camera was positioned in front of the tiestalls $(2.08 \mathrm{~m}$ off the floor and $0.53 \mathrm{~m}$ from the tie rail) such that 2 or 3 heifers could be recorded by each camera. The amount of time spent feeding during the 7-d recording period was scored for individual heifers using instantaneous scan sampling every $5 \mathrm{~min}$. Although Kitts et al. (2011) found that 10-min scans were sufficient $(r=0.95$ in correlation to continuous recording), we wished to increase the accuracy of this measurement by increasing our scanning frequency. For each scan, feeding was defined when a heifer had its head completely past the feed curb and over the feed. Total time spent feeding was then calculated by multiplying the number of scans by 5 . Total time spent feeding was then calculated for each heifer for each day of the 7 -d recording periods and the 2 -d preference period. To identify changes in diurnal feeding patterns between treatments, these scans were used to calculate the percentage of heifers feeding at the feed bunk over a $24-h$ period.

Ruminal temperature was selected as a measurement for rumen health, as opposed to rumen $\mathrm{pH}$, due to the lower level of invasiveness associated with administration of rumen temperature boluses versus cannulation of the rumen for the placement of rumen $\mathrm{pH}$ probes that require regular calibration. The association between rumen temperature and rumen $\mathrm{pH}$ has been validated and discussed elsewhere (AlZahal et al., 2008, 2009). Ruminal temperature was recorded for the last $7 \mathrm{~d}$ of each treatment period using a telemetric acquisition system (SmartStock LLC, Pawnee, OK), which was composed of the following: a telemetric ruminal bolus $(3 \mathrm{~cm}$ in diameter and $8.5 \mathrm{~cm}$ in height, $120 \mathrm{~g}$ in weight), an antenna, a barn receiver unit, a base receiver unit, and a personal computer equipped with a software program for data logging, as validated by AlZahal et al. (2009). Ruminal temperature measurements were broadcasted through a radio frequency (0.3-3.0 GHz) from the bolus to the barn receiver unit through the antenna that was within $100 \mathrm{~m}$ of the heifers. The signal was then transmitted $(0.9 \mathrm{GHz})$ from 
Table 2. Chemical composition, calculated nutrients, and particle-size distribution of the forages (mean \pm $\mathrm{SD}$; DM basis)

\begin{tabular}{|c|c|c|c|c|}
\hline Item & $\begin{array}{c}\text { Grass-alfalfa } \\
\text { haylage }\end{array}$ & $\begin{array}{l}\text { Corn } \\
\text { silage }\end{array}$ & $\begin{array}{l}\text { Long } \\
\text { straw }\end{array}$ & $\begin{array}{l}\text { Short } \\
\text { straw }\end{array}$ \\
\hline \multicolumn{5}{|c|}{ Chemical composition $^{1}(\%)$} \\
\hline $\mathrm{DM}$ & $40.5 \pm 0.1$ & $39.4 \pm 0.1$ & $87.8 \pm 2.5$ & $89.0 \pm 1.5$ \\
\hline $\mathrm{CP}$ & $17.5 \pm 1.1$ & $8.3 \pm 0.2$ & $3.9 \pm 0.2$ & $5.5 \pm 1.8$ \\
\hline $\mathrm{ADF}$ & $34.0 \pm 0.4$ & $18.2 \pm 0.7$ & $59.2 \pm 0.6$ & $55.4 \pm 1.4$ \\
\hline $\mathrm{NDF}$ & $53.6 \pm 0.2$ & $31.0 \pm 0.6$ & $83.4 \pm 0.0$ & $80.8 \pm 1.6$ \\
\hline $\mathrm{NFC}^{2}$ & $15.5 \pm 0.7$ & $54.7 \pm 0.3$ & $8.3 \pm 0.4$ & $8.9 \pm 0.6$ \\
\hline $\mathrm{OM}$ & $88.5 \pm 0.4$ & $96.6 \pm 0.1$ & $95.4 \pm 0.9$ & $95.4 \pm 0.5$ \\
\hline \multicolumn{5}{|c|}{ Calculated nutrients } \\
\hline TDN (\% of DM) & $59.2 \pm 0.4$ & $76.5 \pm 0.0$ & $47.5 \pm 1.3$ & $47.7 \pm 0.1$ \\
\hline ME (Mcal/kg) & $2.14 \pm 0.02$ & $2.76 \pm 0.0$ & $1.72 \pm 0.05$ & $1.72 \pm 0.0$ \\
\hline $\mathrm{NE}_{\mathrm{G}}(\mathrm{Mcal} / \mathrm{kg})$ & $0.72 \pm 0.02$ & $1.21 \pm 0.0$ & $0.34 \pm 0.05$ & $0.35 \pm 0.0$ \\
\hline $\mathrm{NE}_{\mathrm{M}}(\mathrm{Mcal} / \mathrm{kg})$ & $1.29 \pm 0.02$ & $1.83 \pm 0.0$ & $0.87 \pm 0.05$ & $0.88 \pm 0.0$ \\
\hline \multicolumn{5}{|l|}{ Particle size $^{3}(\%)$} \\
\hline Long & $40.8 \pm 5.7$ & $2.0 \pm 1.3$ & $66.1 \pm 8.5$ & $3.6 \pm 1.3$ \\
\hline Medium & $39.6 \pm 3.8$ & $57.3 \pm 0.2$ & $20.8 \pm 5.6$ & $39.7 \pm 7.0$ \\
\hline Short & $17.6 \pm 0.8$ & $39.4 \pm 1.1$ & $12.1 \pm 3.0$ & $49.8 \pm 5.6$ \\
\hline Fine & $2.0 \pm 1.1$ & $1.3 \pm 0.4$ & $1.0 \pm 0.4$ & $6.9 \pm 0.1$ \\
\hline
\end{tabular}

${ }^{1}$ Values were obtained from chemical analysis of feed component samples.

${ }^{2} \mathrm{NFC}=100-(\% \mathrm{NDF}+\% \mathrm{CP}+\%$ ether extract $+\%$ ash $)$.

${ }^{3}$ Particle size determined by Penn State Particle Separator, which has a 19-mm screen (long), 8-mm screen (medium), 1.18-mm screen (short), and a pan (fine).

the barn receiver unit to the base receiver unit (located within $10 \mathrm{~m}$ ), which was connected via a cable to the personal computer. The bolus was administered, using a bolus gun, to each heifer before the start of the study. The bolus was customized to transmit every minute and each transmission included 12 recordings.

Lying behavior was recorded during the 7 -d of each treatment period. Daily lying times of individual heifers were collected using electronic data loggers (Hobo Pendant G Data Logger, Onset Computer Corp., Pocasset, MA), previously validated by Ledgerwood et al. (2010). These devices were placed on the hind leg of each heifer using veterinary bandaging (Vetrap Bandaging Tape, $3 \mathrm{M}$, St. Paul, MN) and measured the orientation of the leg at 1-min intervals. This data was summarized to calculate the average daily standing or lying time (min/d) as well as time spent standing without feeding (i.e., daily standing time - feeding time).

\section{Feed Sampling and Analysis}

Representative grab samples of the TMR were taken for DM and chemical analysis during the $7 \mathrm{~d}$ of each treatment period. Samples of the dietary components were also taken for DM and chemical analysis twice during each of these recording weeks. Duplicate samples of forage components were taken, once during each treatment period, for particle size separation. Grab samples of the TMR were also collected for particle size separation at the time of feed delivery twice weekly during the $7 \mathrm{~d}$ of each treatment period. All samples were immediately frozen at $-20^{\circ} \mathrm{C}$ until they were analyzed (Table 2).

Samples for particle size separation were thawed at a later date and separated using a 3-screen $(19,8,1.18$ mm) Penn State Particle Separator (PSPS; Kononoff et al., 2003). This separated the samples into 4 fractions: long $(\geq 19 \mathrm{~mm})$, medium $(<19$ to $\geq 8 \mathrm{~mm})$, short $(<8$ to $\geq 1.18 \mathrm{~mm})$ and fine $(<1.18 \mathrm{~mm})$ particles. After separation, the DM of each separated fraction was determined by forced air drying at $55^{\circ} \mathrm{C}$ for $48 \mathrm{~h}$.

Samples taken for DM and chemical analysis were oven-dried at $55^{\circ} \mathrm{C}$ for $48 \mathrm{~h}$ and then ground to pass through a 1-mm screen (Wiley Mill, Arthur H. Thomas Co., Philadelphia, PA). These samples were then sent to Cumberland Valley Analytical Services Inc. (Maugansville, MD) for analysis of $\mathrm{DM}\left(135^{\circ} \mathrm{C}\right.$; AOAC International, 2000; method 930.15), ADF (AOAC International, 2000; method 973.18), NDF with heatstable $\alpha$-amylase and sodium sulfite (Van Soest et al., 1991), and $\mathrm{CP}(\mathrm{N} \times 6.25)$ (AOAC International, 2000; method 990.03; Leco FP-528 Nitrogen Analyzer, Leco, St. Joseph, MI).

\section{Calculations and Statistical Analysis}

For analyses of treatment effects, the heifer was considered the experimental unit. Preliminary inspection of the data revealed that all dependent variables were normally distributed. A preliminary analysis of the effect of day within treatment period was conducted for the DMI, feeding behavior, and lying behavior data. 
For this analysis, data were analyzed using the MIXED procedure of (SAS Institute, 2008). The model included the fixed effect of treatment, day, and treatment by day interaction, the random effect of heifer within order, and the residual error. This analysis revealed a day effect; visual assessment of the data suggested that variability within treatments was greatest in the first $4 \mathrm{~d}$ of each treatment period, suggesting heifers were acclimating to their treatment rations. Due to this variability, the first $4 \mathrm{~d}$ of data from each period were excluded; further analysis of the last $3 \mathrm{~d}$ of each treatment period revealed no day effect. Thus, only data from the last 3 $\mathrm{d}$ of each treatment period were considered in further analyses. These data were averaged by treatment period for each heifer. To test for the effect of treatment, data were analyzed using the MIXED procedure of SAS (SAS Institute, 2008). The model included the fixed effect of treatment, period, and order, the random effect of heifer within order, and the residual error.

The preference for type of straw was evaluated through a preference ratio that was calculated as the amount of long straw consumed during the test divided by the total amount of straw consumed. This preference ratio was then tested for a difference from 0.5 using PROC TTEST (SAS Institute, 2008).

Heifers with less than 800 temperature recordings per day were removed from further analysis, as 800 readings per day was believed to be representative of the animal's daily mean, maximum, and minimum rumen temperature as per AlZahal et al. (2008, 2009). Mean, minimum, and maximum daily ruminal temperatures were calculated from all available observations using PROC MEANS of SAS. The duration ( $\mathrm{min} / \mathrm{d}$ ) that ruminal temperature was elevated above a given threshold (i.e., $38.0^{\circ} \mathrm{C}, 38.2^{\circ} \mathrm{C}, 38.4^{\circ} \mathrm{C}$, and so on) was computed to describe the magnitude of elevation in temperature in the rumen (AlZahal et al., 2008). The durations that ruminal temperatures were above a given temperature threshold were calculated for each day of recording using PROC MEANS of SAS. Daily average ruminal temperature data (mean, maximum, minimum, and time above a specific cut-off point) were analyzed using the MIXED procedure of SAS. The model included the fixed effects of period, treatment, and order, the random effect of heifer within order, and the residual error. Interactions of the period with treatment were tested in the model and were not significant; therefore, these are not further reported.

All values reported are least squares means. Significance was declared as $P \leq 0.05$.

\section{RESULTS}

The increase in time spent feeding daily when heifers were fed LS was due to an increase in time spent con- suming straw, rather than TMR (Table 3). This difference in feeding time was due to heifers consuming the straw at a slower rate throughout the day when they were fed LS compared with when they were fed SS, whereas the feeding rate of TMR did not differ between treatments (Table 3). The difference in feeding time between treatments can be seen in Figure 1 and was further confirmed in the analysis of diurnal patterns $(P$ $=0.04$ ). Daily lying time and time spent standing without feeding were similar between treatments (Table 3). Heifers completely consumed all offered TMR each day. Total DMI was similar between heifers, regardless of feed type (TMR or straw; Table 3).

The preference period showed a strong preference ratio for LS rather than SS $(0.83 ; \mathrm{SE}=0.06, P=0.0003)$ with heifers consuming $0.43 \pm 0.2 \mathrm{~kg} / \mathrm{d}$ of LS and 0.07 $\pm 0.1 \mathrm{~kg} / \mathrm{d}$ of SS (mean $\pm \mathrm{SD}$ ). During the preference period, heifers spent $55.3 \pm 18.9 \mathrm{~min} / \mathrm{d}$ consuming LS and $14.6 \pm 10.6 \mathrm{~min} / \mathrm{d}$ consuming SS (mean $\pm \mathrm{SD}$ ).

Heifers maintained similar mean, minimum, and maximum rumen temperatures across treatments (Table 4). The amount of time that rumen temperature was elevated over $38.6^{\circ} \mathrm{C}, 39.0^{\circ} \mathrm{C}$, and $39.4^{\circ} \mathrm{C}$ was also similar between treatments (Table 4).

\section{DISCUSSION}

Previous research has suggested that providing a lownutritive feedstuff alongside a limit-fed TMR (restricted to $70-80 \%$ of ad libitum intake) may help to reduce the negative behavioral effects associated with limit feeding (i.e., reduced time feeding, increased standing without eating) without compromising the feed efficiency to a similar level as ad libitum-fed heifers (Greter et al., 2011; Kitts et al., 2011). It is not clear, however, what the animals are trying to accomplish by consuming the extra feed. Specifically, it is questionable as to whether they are still experiencing hunger and wish to increase rumen fill or whether they desire a foraging substrate in an effort to address a behavioral need to forage or to increase the buffering capacity of the rumen.

The amount of time spent consuming the TMR, as well as the rate at which the TMR was consumed, were similar between treatments. These results were expected, as heifers on either treatment received the same TMR. However, when heifers were fed LS they spent more time feeding throughout the day than when they were fed SS. This increase is due to the longer period of time required to consume the long straw particles, rather than the TMR. The physical characteristics (i.e., particle size) of feed directly affect how quickly a particular feedstuff may be consumed, and thus contributes to heifers spending more time consuming the long particles (Beauchemin et al., 2008). When heifers were 
Table 3. Intake and behavioral data from growing dairy heifers fed a nutrient-dense TMR with either long (LS) or short straw $(\mathrm{SS})^{1}$

\begin{tabular}{|c|c|c|c|c|}
\hline \multirow[b]{2}{*}{ Item } & \multicolumn{2}{|c|}{ Treatment $^{2}$} & \multirow[b]{2}{*}{$\mathrm{SE}$} & \multirow[b]{2}{*}{$P$-value } \\
\hline & LS & SS & & \\
\hline \multicolumn{5}{|l|}{ DMI (kg/d) } \\
\hline Total & 6.7 & 6.7 & 0.4 & 1.0 \\
\hline TMR & 6.3 & 6.3 & 0.4 & 0.3 \\
\hline Straw & 0.34 & 0.37 & 0.06 & 0.7 \\
\hline \multicolumn{5}{|l|}{ Feeding time $(\min / \mathrm{d})$} \\
\hline Total & 197.7 & 175.2 & 5.7 & 0.01 \\
\hline TMR & 137.9 & 141.0 & 4.8 & 0.5 \\
\hline Straw & 59.8 & 34.2 & 5.0 & 0.007 \\
\hline \multicolumn{5}{|l|}{ Feeding rate (kg of $\mathrm{DM} / \mathrm{min})$} \\
\hline TMR & 0.05 & 0.05 & 0.003 & 0.5 \\
\hline Straw & 0.006 & 0.01 & 0.001 & 0.008 \\
\hline Lying time $(\min / \mathrm{d})$ & 969.0 & 980.4 & 11.4 & 0.4 \\
\hline Standing without feeding $(\mathrm{min} / \mathrm{d})$ & 273.3 & 284.4 & 10.4 & 0.4 \\
\hline
\end{tabular}

${ }^{1}$ Data for DMI, feeding times, feeding rates, lying time, and inactive standing time are averaged for 10 heifers over $3 \mathrm{~d}$ on each treatment.

${ }^{2}$ Treatments were provisions of LS and SS at $1600 \mathrm{~h}$ following consumption of a nutrient-dense TMR offered at $1100 \mathrm{~h}$.

fed LS they also consumed their feed at a slower rate across the day. This is consistent with other research on feed particle size and feeding behavior. Kenney and Black (1984) found that increasing straw length from 10 to $30 \mathrm{~mm}$ decreased the rate of eating in sheep, a reflec- tion of the increased time required to chew the longer particles. Providing straw alongside of a limit-fed TMR (restricted to $70-80 \%$ of ad libitum intake) increases overall time spent feeding (Greter et al., 2011; Kitts et al., 2011) and helps to return feeding patterns to those

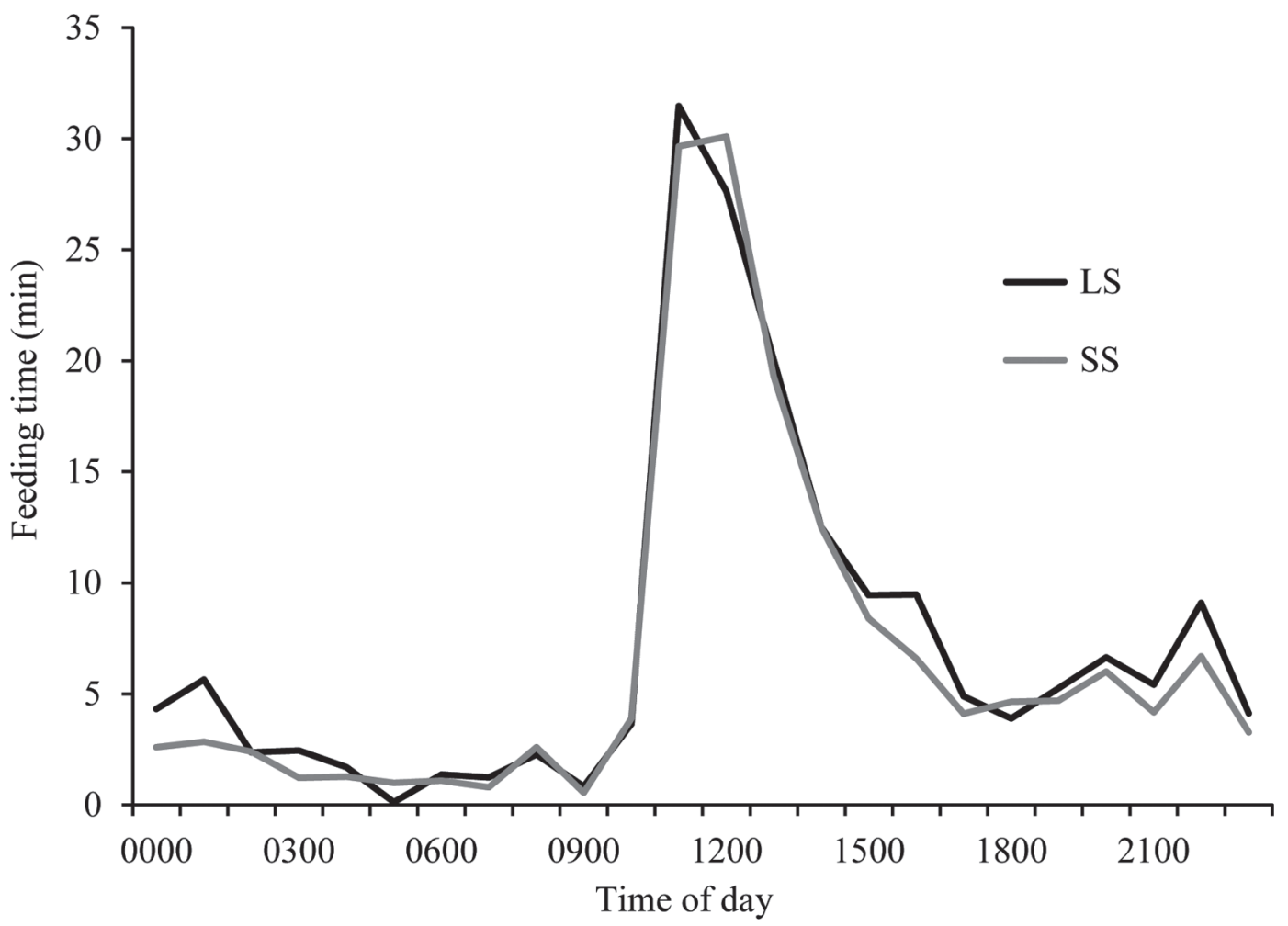

Figure 1. Hourly average for feeding time ( $\min )$ of dairy heifers on 2 treatments. Treatments were provisions of long straw (LS) and short straw (SS) at $1600 \mathrm{~h}$ following consumption of a nutrient-dense TMR offered at $1100 \mathrm{~h}$. Data are averaged across $3 \mathrm{~d}$ for 10 heifers on each treatment. 
Table 4. Least squares means for ruminal temperature characteristics obtained by a telemetric monitoring system for growing dairy heifers fed a nutrient-dense TMR with either long (LS) or short straw (SS) ${ }^{1}$

\begin{tabular}{lcccc}
\hline & \multicolumn{2}{c}{ Treatment $^{2}$} & & \\
\cline { 2 - 3 } Item & $\mathrm{LS}$ & $\mathrm{SS}$ & $\mathrm{SE}$ & $P$-value \\
\hline Mean $\left({ }^{\circ} \mathrm{C}\right)$ & 38.3 & 38.3 & 0.1 & 0.4 \\
Maximum $\left({ }^{\circ} \mathrm{C}\right)$ & 38.9 & 38.9 & 0.1 & 0.8 \\
Minimum $\left({ }^{\circ} \mathrm{C}\right)$ & 35.1 & 35.0 & 0.3 & 0.4 \\
Duration $(\mathrm{min} / \mathrm{d})$ & 353.2 & 324.6 & 131.6 & 0.3 \\
$>38.6^{\circ} \mathrm{C}$ & 209.7 & 162.5 & 100.6 & 0.3 \\
$>39.0^{\circ} \mathrm{C}$ & 3.1 & 11.0 & 7.2 & \\
$>39.4^{\circ} \mathrm{C}$ & &
\end{tabular}

observed in ad libitum-fed animals ( $3-5 \mathrm{~h}$; Greter et al., 2008; DeVries and von Keyserlingk, 2009). This effect is enhanced when feeding LS, as opposed to SS, due to the increase in time spent feeding. We were unable to measure rumination in this study, but time spent ruminating is often similar to time spent feeding and it is likely that heifers fed LS would spend more time ruminating as well. As feeding and rumination time make up feeding behavior, an increase in either of these factors would likely help to alleviate frustration (i.e., indicators such as redirected licking of the pen or companions, stereotypical locomotory or oral behaviors, or vocalizations) due to lack of foraging as well as hunger from lack of rumen fill (D'Eath et al., 2009).

Despite this difference in feeding time, when heifers were fed LS they did not spend less time lying or standing without feeding compared with when they were fed SS. The variability in lying time among animals may account for this lack of difference in lying and standing behavior. Additionally, an increase in arousal is seen more often in animals that are feed restricted, (restricted to $80-85 \%$ of ad libitum intake; Redbo et al., 1996; Redbo and Nordblad, 1997), and is a response that may be used as an indicator of hunger in other species (rats, Le Magnen, 1985; pigs, Terlouw et al., 1991). Heifers in this study were provided a limited amount of TMR (consumed at $84 \%$ of predicted ad libitum intake) but given ad libitum access to straw. Therefore, these heifers were not truly limit-fed, regardless of the particle size of the straw, and may not show a difference in lying or inactive activity as they had access to feed at all times.

The rumen temperature was similar between treatments and, overall, was rarely high enough to suggest acidotic rumen conditions ( $>39.2$; AlZahal et al., 2009). Heifers that are limit-fed may experience a low $\mathrm{pH}$ following a feeding event as a nutrient-dense TMR typically contains a high percentage of rapidly fermentable carbohydrates (5.3; Lascano and Heinrichs, 2009).
Heifers in this study did not encounter this depression in $\mathrm{pH}$, as measured by rumen temperature. This may be due to the relatively high forage to concentrate ratio of the limit-fed TMR (63:37), as well as to the straw offered ad libitum. Although the LS had a greater percentage of long particles, $40 \%$ of the particles from the SS were retained on the top 2 screens of the PSPS. As physically effective fiber (PEF) is considered to be the long and medium particles from the PSPS, the SS was still fairly high in PEF. Physically effective fiber helps to increase the buffering capacity of the rumen by increasing the bicarbonate and phosphate buffers through an increase in saliva secretion during chewing (Allen, 1997; Beauchemin et al., 2008). Krause and Combs (2003) also found that difference in particle size did not affect rumen $\mathrm{pH}$. It was speculated that, similar to the current study, the difference in particle size between treatments was not drastic enough to affect rumen $\mathrm{pH}$. Although rumen temperature was not negatively affected in this study, the potential for problems to arise with rumen fermentation due to limit feeding exists. Care should be taken to ensure that the ration contains sufficient levels of PEF and that heifers are transitioned over a period of 10 to $14 \mathrm{~d}$ (Lascano and Heinrichs, 2009). Further research examining the effect of a lower forage to concentrate ratio in conjunction with a lack of PEF is necessary to understand the effect of a nutrient-dense ration with supplementary roughage (i.e., straw) on the rumen. Additionally, these results must be interpreted with caution, as without more detailed sampling methods utilizing repeated measures of ruminal $\mathrm{pH}$, the true effect of these treatments on rumen health cannot be determined on a diurnal basis.

As the TMR portion of the ration was provided in a controlled, limited amount, it is not surprising that the amount consumed did not differ between treatments. However, heifers consumed similar amounts of LS or SS, suggesting that they were willing to eat whatever is available to them in an attempt to increase rumen 
fill or spend more time foraging. Continued arousal following feeding likely indicates that the animal is still experiencing hunger and that either physical, metabolic, or both requirements have not been met by the feed consumed (D'Eath et al., 2009). Indeed, evidence exists to suggest that satiety in cattle is not only linked to the amount of feed consumed, but also to the duration of feeding. Lindström and Redbo (2000) found that, whether the rumen was full or not, lactating dairy cows were motivated to orally manipulate their feed, suggesting that the act of feed manipulation contributes to the negative feedback loop in decreasing the animals' motivation to feed. In our study, heifers consumed LS or SS in similar amounts, indicating that either feedstuff was able to provide some satisfaction to their foraging needs. Kitts et al. (2011) found that the provision of straw (provided at $1.8 \mathrm{~kg} \mathrm{DM} /$ heifer each day) alongside a TMR fed in a limited amount resulted in heifers increasing their total DMI to their predicted ad libitum intake level. Thus, it was concluded that the straw provided sufficient bulk and feeding time to decrease the heifers' motivation to feed and these animals were assumed to be satiated. Similarly, heifers in this study were provided with straw ad libitum. Interestingly, straw was consumed in addition to the TMR up to only $90 \%$ of predicted ad libitum intake. Thus, it could be assumed that all animals' foraging needs or gut fill were sufficiently satisfied when provided with either straw length.

Despite the fact that heifers will eat either straw length, they did show a very clear preference for the LS when given the choice. The LS contained a much greater percentage of long and medium particles than the SS (80 vs. $40 \%$ ). It is possible that the heifers derived more satisfaction from the oral manipulation of these long particles, which required more chewing and subsequent rumination than the short particles. Additionally, the LS likely contributed much more to rumen fill (Allen, 1996) than the SS, helping heifers fed LS to feel physically full for a longer period of time. Castle et al. (1979) found that dairy cows will consume more DM and increase milk production when fed short particle silage in comparison to medium and long particle silage, but that they will eat significant amounts of the latter 2 foods when given a choice. Sheep have also been shown to consume considerable quantities of long forage (i.e., hay), even though it takes more time and effort to harvest, chew, and digest than a concentrate offered ad libitum (Forbes and Kyriazakis, 1995). As limit-fed rations often contain a high percentage of ground forage or concentrate (short particles), it is possible that these animals prefer the LS in an effort to increase their consumption of longer forage particles. The SS was also higher in fine particles and was, thus, more dusty than the LS. Jarridge et al. (1973) performed many measurements on voluntary intake and feeding behavior of on chopped and ground forages and found that when the mean particle size of the forage was reduced to $0.75 \mathrm{~mm}$ or smaller, voluntary intake decreased. As such, heifers in the current study may have also been showing an aversion to the higher proportion of very small particles found in the SS in this study, resulting in an exaggerated preference for LS.

Finally, although no differences were observed in rumen temperature between treatments, it is possible that temperature increases ( $\mathrm{pH}$ depressions) throughout the day were short in duration and would not be captured by the equipment, as the boluses did not transmit as frequently when heifers were lying down. Animals have been shown to develop preferences for a feedstuff based on its ability to ameliorate malaise. Keunen et al. (2002) found that following induction of subacute ruminal acidosis, dairy cattle offered alfalfa pellets and long alfalfa hay altered their feeding in preference of the long hay. These researchers speculated that this was likely due to the increased buffering capacity of long hay due to increased chewing resulting in increased salivary secretion. Thus, the cows were selecting the alternative that would best attenuate the acidosis (Keunen et al., 2002).

\section{CONCLUSIONS}

Heifers will choose to consume supplementary straw when it is provided to them in addition to a nutrientdense TMR fed in a limited amount. Although they consume similar amounts of either LS or SS, they spend more time consuming the LS at a slower rate across the day. Rumen temperature was not affected by feeding either LS or SS, suggesting that both straw lengths contained sufficient levels of physically effective fiber. When given the choice, heifers prefer to consume LS, perhaps in an effort to maximize their foraging needs or to increase satiety through sufficient rumen fill. It is recommended to offer a supplementary low-nutritive feedstuff alongside of a TMR to allow limit-fed heifers to engage in feeding patterns more conducive to natural behavior and to alleviate frustration and hunger due to insufficient foraging or rumen fill.

\section{ACKNOWLEDGMENTS}

We thank the staff and students at the University of Guelph, Kemptville Campus Dairy Education and Research Centre, particularly Megan Bruce, Morgan Overvest, and John Wynands for their technical help and support. Angela Greter was supported by a Natural Sciences and Engineering Research Council of Canada (NSERC, Ottawa, ON, Canada) Alexander Graham 
Bell Canadian Graduate Scholarship. This project was funded through an Ontario Ministry of Agriculture, Food and Rural Affairs (OMAFRA)/University of Guelph Production Systems research grant and a Campbell Centre for the Study of Animal Welfare (University of Guelph, Guelph, ON, Canada) research grant. This project was also supported through contributions from the Canadian Foundation for Innovation (CFI, Ottawa, ON, Canada) and the Ontario Research Fund (Ministry of Research and Innovation, Toronto, ON, Canada).

\section{REFERENCES}

Allen, M. S. 1996. Physical constraints on voluntary intake of forages by ruminants. J. Anim. Sci. 74:3063-3075.

Allen, M. S. 1997. Relationship between fermentation acid production in the rumen and the requirement for physically effective fiber. J Dairy Sci. 80:1447-1462.

AlZahal, O., E. Kebreab, J. France, M. Froetschel, and B. W. McBride. 2008. Ruminal temperature may aid in the detection of subacute ruminal acidosis. J. Dairy Sci. 91:202-207.

AlZahal, O., M. A. Steele, E. V. Valdes, and B. W. McBride. 2009. Technical note: The use of a telemetric system to continuously monitor ruminal temperature and to predict ruminal $\mathrm{pH}$ in cattle. J. Dairy Sci. 92:5697-5701.

AOAC International. 2000. Official Methods of Analysis. Vol. I. 17th ed. AOAC International, Arlingtion, VA.

Beauchemin, K. A., L. Eriksen, P. Nørgaard, and L. M. Rode. 2008. Salivary secretion during meals in lactating dairy cattle. J. Dairy Sci. 91:2077-2081

Canadian Council on Animal Care. 2009. Guidelines On: The Care and Use of Farm Animals in Research, Teaching and Testing. Canadian Council on Animal Care, Ottawa, Canada.

Castle, M. E., W. C. Retter, and J. N. Watson. 1979. Silage and milk production: Comparisons between grass silage of three different chop lengths. Grass Forage Sci. 34:293-301.

D'Eath, R. B., B. J. Tolkamp, I. Kyriazakis, and A. B. Lawrence. 2009. 'Freedom from hunger' and preventing obesity: The animal welfare implications of reducing food quantity or quality. Anim. Behav. 77:275-288.

DeVries, T. J., and M. A. G. von Keyserlingk. 2009. Feeding method affects the feeding behavior of growing dairy heifers. J. Dairy Sci. 92:1161-1168.

Forbes, J. M. 2007. Voluntary Food Intake and Diet Selection of Farm Animals. 2nd ed. CABI Publishing, Oxfordshire, UK.

Forbes, J. M., and I. Kyriazakis. 1995. Food preferences in farm animals: Why don't they always choose wisely? Proc. Nutr. Soc. 54:429-440.

Greter, A. M., T. J. DeVries, and M. A. G. von Keyserlingk. 2008. Nutrient intake and feeding behavior of growing dairy heifers: Effects of dietary dilution. J. Dairy Sci. 91:2786-2795.

Greter, A. M., B. L. Kitts, and T. J. DeVries. 2011. Limit feeding dairy heifers: Effect of feed bunk space and provision of a low-nutritive feedstuff. J. Dairy Sci. 94:3124-3129.

Hoffman, P. C., C. R. Simson, and M. Wattiaux. 2007. Limit feeding of gravid Holstein heifers: Effect on growth, manure nutrient excretion, and subsequent early lactation performance. J. Dairy Sci. 90:946-954.

Jarridge, R., C. Demarquilly, M. Journet, and C. Beranger. 1973. The nutritive value of processed dehydrated forages with special reference to the influence of physical form and size particle. Pages 99-118 in Proc. First Int. Green Crop Dry. Congr. E\&E Plumridge, Cambridge, UK.
Kenney, P., and J. L. Black. 1984. Factors affecting diet selection by sheep. I. Potential intake rate and acceptability of food. Aust. J. Agric. Res. 35:5511-5563.

Kertz, A. F., and H. Chester-Jones. 2004. Guidelines for measuring and reporting calf and heifer experimental data. J. Dairy Sci. $87: 3577-3580$

Keunen, J. E., J. C. Plaizier, I. Kyriazakis, T. F. Duffield, T. M. Widowski, M. I. Linginger, and B. W. McBride. 2002. Effects of a subacute ruminal acidosis model on the diet selection of dairy cows. J. Dairy Sci. 85:3304-3313.

Kilgour, R. J. 2012. In pursuit of "normal": A review of the behaviour of cattle at pasture. Appl. Anim. Behav. Sci. 138:1-11.

Kitts, B. L., I. J. H. Duncan, B. W. McBride, and T. J. DeVries. 2011 Effect of the provision of a low-nutritive feedstuff on the behavior of dairy heifers fed a nutrient-dense ration in a limited amount. J. Dairy Sci. 94:940-950.

Kononoff, P. J., A. J. Heinrichs, and D. R. Buckmaster. 2003. Modification of Penn State forage and total mixed ration particle separator and the effects of moisture content on its measurements. J. Dairy Sci. 86:1858-1863.

Krause, K. M., and D. K. Combs. 2003. Effects of forage particle size, forage source, and grain fermentability on performance and ruminal $\mathrm{pH}$ in midlactation cows. J. Dairy Sci. 86:1382-1397.

Lascano, G. J., and A. J. Heinrichs. 2009. Rumen fermentation pattern of dairy heifers fed restricted amounts of low, medium, and high concentrate diets without and with yeast culture. Livest. Sci. 124:48-57.

Lascano, G. J., G. I. Zanton, F. X. Suarez-Mena, and A. J. Heinrichs. 2009. Effect of limit feeding high- and low-concentrate diets with Saccharomyces cerevisiae on digestibility and on dairy heifer growth and first-lactation performance. J. Dairy Sci. 92:51005110

Le Magnen, J. 1985. Hunger (Problems in the Behavioural Sciences). Cambridge University Press, Cambridge, UK.

Ledgerwood, D. N., C. Winckler, and C. B. Tucker. 2010. Evaluation of data loggers, sampling intervals, and editing techniques for measuring the lying behavior of dairy cattle. J. Dairy Sci. 93:5129-5139.

Lindström, T., and I. Redbo. 2000. Effect of feeding duration and rumen fill on behaviour in dairy cows. Appl. Anim. Behav. Sci 70:83-97.

Moody, M. L., G. I. Zanton, J. M. Daubert, and A. J. Heinrichs. 2007. Nutrient utilization of differing forage-to-concentrate ratios by growing Holstein heifers. J. Dairy Sci. 90:5580-5586.

Morris, T. R. 1999. Experimental Design and Analysis in Animal Sciences. CABI Publishing, New York, NY.

NRC. 2001. Nutrient Requirements of Dairy Cattle. Natl. Acad. Sci., Washington, DC.

Redbo, I., M. Emanuelson, K. Lundberg, and N. Oredsson. 1996. Feeding level and oral stereotypies in dairy cows. Anim. Sci. 62:199206.

Redbo, I., and A. Nordblad. 1997. Stereotypies in heifers are affected by feeding regime. Appl. Anim. Behav. Sci. 53:193-202.

SAS Institute. 2008. User's Guide: Statistics. Version 9.1.3 ed. SAS Institute Inc., Cary, NC.

Savory, C. J., K. Maros, and S. M. Rutter. 1993. Assessment of hunger in growing broiler breeders in relation to a commercial restricted feeding program. Anim. Welf. 2:131-152.

Stone, W. C. 2004. Nutritional approaches to minimize subacute ruminal acidosis and laminitis in dairy cattle. J. Dairy Sci. 87(E. Suppl.):E13-E26.

Terlouw, E. M. C., A. B. Lawrence, and A. W. Illius. 1991. Influences of feeding level and physical restriction on development of stereotypies in sows. Anim. Behav. 42:981-991.

Van Soest, P. J., J. B. Robertson, and B. A. Lewis. 1991. Methods for dietary fiber, neutral detergent fiber and nonstarch polysaccharides in relation to animal nutrition. J. Dairy Sci. 74:3583-3597. 